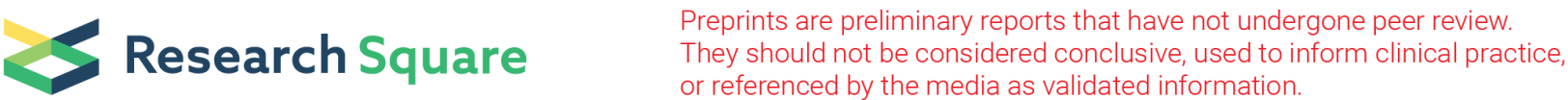 \\ Multivariate Logistic Regression Analysis of the Outcomes After Humeral Head Replacement: A Case Series
}

\section{Chunhui Chen}

The Second Affiliated Hospital and Yuying Children's Hospital of Wenzhou Medical University

\section{Xingyu Wang}

The Second Affiliated Hospital and Yuying Children's Hospital of Wenzhou Medical University

Xubo Lin ( $\square$ Ixb-77@163.com )

The Second Affiliated Hospital and Yuying Children's Hospital of Wenzhou Medical University

\section{Research article}

Keywords: humeral head replacement, surgery effect, logistic analysis, factors

Posted Date: November 24th, 2020

DOI: https://doi.org/10.21203/rs.3.rs-111906/v1

License: (c) (i) This work is licensed under a Creative Commons Attribution 4.0 International License.

Read Full License 


\section{Abstract}

Background: The aim of our study was to explore the risk factors affecting the treatment of humeral head replacement.

Methods: 52 patients with humeral head replacement surgery were enrolled in the study. The information of patients were recorded. The treatment outcomes of humeral head replacement were evaluated by ASES scores. The indicators that may affect humeral head arthroplasty surgery effect were analyzed by univariate analysis and multivariate logistic regression analysis.

Results: Univariate analysis showed: the differences of age, time from injury to surgery, time to start exercising after surgery, whether the patient regular follow-up, visual Analogue Scale(VSA), whether with shoulder dislocation, and whether with osteoporosis, were statistically significant $(P<0.05)$. Multivariate Logistic regression analysis showed that age, time from injury to surgery, whether with shoulder dislocation, time to start exercising after surgery, and whether the patient regular follow-up were the influencing factors, but whether with osteoporosis and VSA were not illustrated as a risk factor.

Conclusion: Age, time from injury to surgery, time to start exercising after surgery, whether with shoulder dislocation, and whether the patient regular follow-up may be the chief factors affecting humeral head replacement surgery.

Trial Registration: This trial was registered at the Research Registry on June 22, 2018(researchregistry3243, https://www.researchregistry.com/browse-the-registry).

\section{Background}

Proximal humeral fractures are a common clinical fracture, accounting for $4 \%-5 \%$ of the whole body fracture, with $20 \%$ 30\% are complex, displaced, and unstable fracture[1-3]. With the aging of the society, proximal humeral fractures become more and more common in elder patients with osteoporosis[4], and the incidence of proximal humeral fracture increased gradually for elder patients over the age of 60 year old[5]. Known possible consequences of proximal humerus fractures include impaired shoulder function, decreased independence, and increased risk for mortality, especially Neer four-part fracture and Neer three-part fracture[6]. The primary goal of therapy is to relieve pain of limb, restore function of shoulder joint. The traditional method of internal fixation has a high failure rate of fracture reduction, poor recovery of postoperative shoulder function, especially Neer four-part fractures[7]. Thus, more and more scholars advocated the use of artificial humeral head for the treatment of complex proximal humeral fracture, because of significant improvement of humeral head replacement skills and the progress of prosthesis design $[8,9]$.

However, there were some studies $[10,11]$ which reported that the outcome of humeral head replacement was not very satisfied. Frombach, et al.[12] found when operative treatment is indicated, surgical fixation is often difficult or impossible to obtain. Hemiarthroplasty has long been the standard of care. However, 
with its reliance on tuberosity healing, functional outcomes and patient satisfaction are often poor. Hasan et al[13] reported on 139 consecutive patients who were dissatisfied with their shoulder replacement; $74 \%$ described stiffness, and 35\% complained of instability. They suggested that the complications of humeral head replacement could not be ignored such as significant postoperative pain, motion limited, and instability. In order to improve the efficacy, the factors affecting the treatment of humeral head replacement should be further explored. So, this study recruited 52 patients who had underwent humeral head replacement surgery in our hospital from January 2011 to January 2014, and the purpose of this retrospective study is to investigate the risk factors on the treatment of humeral head replacement. And we hypothesized that age, sex, cause of injury, type of fracture, time from injury to surgery, time to start exercising after surgery, visual Analogue Scale(VSA), whether with shoulder dislocation, whether with cerebral infarction history, whether the patient regular follow-up, whether with osteoporosis, whether with diabetes, and whether with cervical spondylosis were significant risk factors for the treatment of humeral head replacement.

\section{Methods}

\subsection{Study design}

We conducted a retrospective review using data drawn from the electronic medical records retained by our medical institution. The study was approved by the institutional review and ethics committee of our hospital. The patients who underwent the treatment of humeral head replacement from January 2011 to January 2014 were enrolled for data collection and analysis. The work has been reported in line with the PROCESS criteria[14]. This trial was registered at the Research Registry on June 22, 2018(researchregistry3243, https://www.researchregistry.com/browse-the-registry).

\subsection{Inclusion criteria and Exclusion criteria}

The inclusion criteria were as follows: (1) Aged 55-80 years; (2) Fresh closed fracture; (3) Neer III and IV type fracture; (4) time from surgery to data collection more than 2 years; (5) surgery completed by the same group. Exclusion criteria: (1) Open, old, and pathological fracture; (2) With important neural and vascular and organ injury; (3) Ipsilateral shoulder congenital malformation; (4) Combined with other parts of the ipsilateral limbs fracture.

\subsection{Data Collection}

We would contact to all patients who meet the exclusion criteria and inclusion criteria by phone to evaluate the effect of humeral head replacement, using the American Association of Shoulder and Elbow Surgery score (ASES score)[15]. According to the outcomes of ASES score, the patients were divided into the superior group and the inferior group. Patients with ASES score greater than or equal to 80 points was the superior group; patients with ASES score less than 80 points was the inferior group. The information of patients such as age, sex, cause of injury, type of fracture, time from injury to surgery, time to start exercising after surgery, visual Analogue Scale (VSA), whether with shoulder dislocation, whether with 
cerebral infarction history, whether the patient regular follow-up, whether with osteoporosis, whether with diabetes and whether with cervical spondylosis were recorded both the superior group and the inferior group.

\subsection{Statistical analysis}

Mean comparison and Chi - square test were used to analysis the single factor (age, sex, cause of injury, type of fracture, time from injury to surgery, time to start exercising after surgery, visual Analogue Scale (VSA) [16], whether with shoulder dislocation, whether with cerebral infarction history, whether the patient regular follow-up, whether with osteoporosis, whether with diabetes and whether with cervical spondylosis) to determine the effect of single factor on the results without considering the intermixing of the factors; then the statistically different factors of univariate analysis were analyzed by multivariate logistic regression. A p-value of less than 0.05 indicated statistically significant result, and all confidence intervals were reported in the 95\% range. Statistical analysis was conducted using SPSS 22 (SPSS Inc., Chicago, IL, USA.).

\section{Result}

\subsection{Study Population}

A total 83 patients who had underwent humeral head replacement were recorded in our hospital database. Of these 83 patients, 64 patients could be in touch and 52(62.7\%) patients were willing to participate in our study. The characteristics of the 52 patients were shown in Table 1. In the superior group, there were 6 men and 24 women with a mean age of $64.33 \pm 6.74$ years (range, 48 to 72 years). According to the NEER classification[17], there were 8 Type-III fractures and 22 Type-IV fractures. Falling down ( 22 fractures) was the primary injury mechanisms, besides car accident ( 8 fractures). The average time from initial injury to operation was $8.40 \pm 6.30$ days in the superior group. And the time to start exercising after surgery was $21.63 \pm 17.72$ days. The inferior group consisted of 4 men and 18 women with an average age of $69.95 \pm 8.64$ years (range, 50 to 84 years). Four Type-III fractures and 18 Type-IV fractures were in this group. Similarly, the injury mechanisms were also falling down (18 fractures) and car accident (4 fractures). The average time from initial injury to operation was $12.59 \pm 7.82$ days. The time to start exercising after surgery was $55.32 \pm 28.92$ days. 
Table 1

The outcomes of univariate analysis

\begin{tabular}{|c|c|c|c|c|}
\hline Risk factors & $\begin{array}{l}\text { Superior } \\
\text { group }\end{array}$ & $\begin{array}{l}\text { Inferior } \\
\text { group }\end{array}$ & $\begin{array}{l}\chi^{2} \text { or } t \\
\text { value }\end{array}$ & $P$ value \\
\hline N & 30 & 22 & - & - \\
\hline Age (years) & $64.33 \pm 6.74$ & $69.95 \pm 8.64$ & $\mathrm{~T}=2.637$ & $P=0.011^{*}$ \\
\hline \multicolumn{5}{|l|}{ Sex } \\
\hline Male & 6 & 4 & $\chi^{2}=0.027$ & $P=0.869$ \\
\hline Female & 24 & 18 & & \\
\hline \multicolumn{5}{|l|}{ Cause of injury } \\
\hline Traffic accident & 8 & 4 & $\chi^{2}=0.515$ & $P=0.473$ \\
\hline Fall & 22 & 18 & & \\
\hline \multicolumn{5}{|l|}{ Type of fracture } \\
\hline Neer III & 8 & 4 & $\chi^{2}=0.515$ & $P=0.473$ \\
\hline Neer IV & 22 & 18 & & \\
\hline Time from injury to surgery (day) & $8.40 \pm 6.30$ & $12.59 \pm 7.82$ & $\mathrm{~T}=2.139$ & $P=0.037 *$ \\
\hline $\begin{array}{l}\text { Time to start exercising after surgery } \\
\text { (day) }\end{array}$ & $21.63 \pm 17.72$ & $\begin{array}{l}55.32 \pm \\
28.92\end{array}$ & $\mathrm{~T}=5.196$ & $P=0.000 *$ \\
\hline Visual Analogue Scale (VSA) & $6.43 \pm 2.01$ & $7.59 \pm 1.53$ & $\mathrm{~T}=3.009$ & $P=0.025^{\star}$ \\
\hline \multicolumn{5}{|l|}{ Whether the patient regular follow-up } \\
\hline Yes & 21 & 6 & $\chi^{2}=7.650$ & $P=0.006 *$ \\
\hline No & 9 & 16 & & \\
\hline \multicolumn{5}{|l|}{ Whether with osteoporosis } \\
\hline Yes & 8 & 16 & $\chi^{2}=71.779$ & $P=0.000 *$ \\
\hline No & 22 & 6 & & \\
\hline \multicolumn{5}{|l|}{ Whether with shoulder dislocation } \\
\hline Yes & 4 & 11 & $\chi^{2}=31.981$ & $P=0.000 *$ \\
\hline No & 26 & 11 & & \\
\hline
\end{tabular}




\begin{tabular}{|lllll|}
\hline Risk factors & $\begin{array}{l}\text { Superior } \\
\text { group }\end{array}$ & $\begin{array}{l}\text { Inferior } \\
\text { group }\end{array}$ & $\begin{array}{l}\chi^{2} \text { or } t \\
\text { value }\end{array}$ & P-value \\
\hline $\begin{array}{l}\text { Whether with cerebral infarction } \\
\text { history }\end{array}$ & 3 & 1 & $\chi^{2}=0.532$ & $P=0.466$ \\
Yes & 27 & 21 & & \\
No & & & $\chi^{2}=0.090$ & $P=0.765$ \\
Whether with diabetes & 5 & 3 & & \\
Yes & 25 & 19 & & \\
No & & & $\chi^{2}=0.001$ & $P=0.975$ \\
Whether with cervical spondylosis & 4 & 3 & & \\
Yes & 26 & 19 & & \\
No & & & & \\
\hline
\end{tabular}

\subsection{Univariate analysis}

Single factor analysis showed that the differences of age, time from injury to surgery, time to start exercising after surgery, whether the patient regular follow-up, VAS $(6.43 \pm 2.01$ in superior group VS 7.59 \pm 1.53 in inferior group), whether with shoulder dislocation (superior group: 4 yes and 26 no; inferior group: 11 yes and 11 no) and whether with osteoporosis (superior group: 8 yes and 22 no; inferior group: 16 yes and 6 no ), were statistically significant $(P<0.05)$; the differences of gender, cause of injury, type of fracture, whether with cerebral infarction history, whether with diabetes and whether with cervical spondylosis were no significant difference $(P>0.05)$, as shown Table 1 .

\subsection{Multivariate logistic regression analysis}

We took the factors that single factor analysis showed statistical significance as the independent variables in the Logistic regression analysis by Enter analysis model. The value of independent variables was reassigned in Table 2. Multiple logistic regression analysis showed that the influencing factors for surgical treatment of humeral head replacement were age $(P=0.018, O R=51.120)$, time from injury to surgery $(P=0.037, O R=18.411)$, whether with shoulder dislocation $(P=0.048, O R=12.972)$, time to start exercising after surgery $(P=0.025, O R=16.772))$, and whether the patient regular follow-up $(P=0.041$, $\mathrm{OR}=0.088$ ). But whether with osteoporosis and visual Analogue Scale (VSA) were not illustrated as a risk factor $(P=0.785, O R=1.419 ; P=0.882, O R=1.239)$ in Table 3. 
Table 2

The reassignment value of variables

\begin{tabular}{|ll|}
\hline variables & Value \\
\hline Age $\left(X_{1}\right)$ & $0-70=0,71-100=1$ \\
\hline Time from injury to surgery $\left(X_{2}\right)$ & $1-7=0,8-20=1$ \\
\hline Time to start exercising after surgery $\left(X_{3}\right)$ & $1-30=0,31-90=1$ \\
\hline Visual Analogue Scale $\left(X_{4}\right)$ & $0-6=0,7-10=1$ \\
\hline Whether the patient regular follow-up $\left(X_{5}\right)$ & NO $=0, Y E S=1$ \\
\hline Whether with osteoporosis $\left(X_{6}\right)$ & NO $=0, Y E S=1$ \\
\hline Whether with shoulder dislocation $\left(X_{7}\right)$ & NO $=0, Y E S=1$ \\
\hline Whether with cerebral infarction history $\left(X_{8}\right)$ & NO $=0, Y E S=1$ \\
\hline Whether with diabetes $\left(X_{9}\right)$ & NO $=0, Y E S=1$ \\
\hline Whether with cervical spondylosis $\left(X_{10}\right)$ & NO $=0, Y E S=1$ \\
\hline$Y$ & Superior group $=0$, Inferior group $=1$ \\
\hline
\end{tabular}

Table 3

The result of multivariate logistic regression analysis

\begin{tabular}{|c|c|c|c|c|c|c|c|}
\hline variables & B & S.E & $\begin{array}{l}\text { Wald } \\
x^{2}\end{array}$ & df & P-value & $\begin{array}{l}\text { OR- } \\
\text { value }\end{array}$ & $95 \% \mathrm{Cl}$ \\
\hline Age & 3.934 & 1.665 & 5.584 & 1 & $\begin{array}{l}P= \\
0.018^{*}\end{array}$ & 51.120 & $(1.956,1335.77)$ \\
\hline Time from injury to surgery & 2.913 & 1.399 & 3.333 & 1 & $\begin{array}{l}P= \\
0.037 *\end{array}$ & 18.411 & $(1.186,285.917)$ \\
\hline $\begin{array}{l}\text { Time to start exercising } \\
\text { after surgery }\end{array}$ & 2.820 & 1.255 & 5.050 & 1 & $\begin{array}{l}P= \\
0.025^{*}\end{array}$ & 16.772 & $(1.434,196.192)$ \\
\hline $\begin{array}{l}\text { Visual Analogue Scale } \\
\text { (VSA) }\end{array}$ & 0.214 & 1.443 & 0.022 & 1 & $\begin{array}{l}P= \\
0.882\end{array}$ & 1.239 & $(0.073,20.952)$ \\
\hline $\begin{array}{l}\text { Whether the patient regular } \\
\text { follow-up }\end{array}$ & -2.431 & 1.188 & 4.187 & 1 & $\begin{array}{l}P= \\
0.041 *\end{array}$ & 0.088 & $(0.009,0.903)$ \\
\hline Whether with osteoporosis & 0.350 & 1.285 & 0.074 & 1 & $\begin{array}{l}P= \\
0.785\end{array}$ & 1.419 & $(0.114,17.592)$ \\
\hline $\begin{array}{l}\text { Whether with shoulder } \\
\text { dislocation }\end{array}$ & 2.563 & 1.289 & 3.898 & 1 & $\begin{array}{l}P= \\
0.048^{*}\end{array}$ & 12.972 & $(1.019,165.133)$ \\
\hline
\end{tabular}




\section{Discussion}

The current indications for primary hemiarthroplasty include a displaced and translated four-part fracture, with or without associated dislocation of the humeral head, and a head-splitting fracture with involvement of $>40 \%$ of the articular surface. [18]. There are many factors associated with the treatment of humeral head replacement. In order to avoid mutual interference between the various factors, the current study used univariate analysis combined with multivariate Logistic regression analysis to investigate the risk factors for the treatment of humeral head replacement [19-21]. Currently, the insufficient bony healing of displaced tuberosities after intra-operative fixation at the stem of the prosthesis, malpositioning of the tuberosity fragments, and incorrect positioning of the prosthesis are probably the most important factors determining the outcomes of this treatment modality[22-24]. In this study, the same team made the surgeries, it can effectively reduce the error caused by surgical operations, especially tuberosity fragments and positioning of the prosthesis. This study confirmed patient factors that age $(P=0.018, O R=51.120)$, time from injury to surgery $(P=0.037, O R=18.411)$, whether with shoulder dislocation $(P=0.048, O R=12.972)$, time to start exercising after surgery $(P=0.025, O R=$ 16.772)), and whether the patient regular follow-up $(P=0.041, O R=0.088)$ were risk factors for treatment of humeral head replacement.

This study showed that age was the first risk factor for treatment of humeral head replacement, with OR $=51.120, P<0.05$. Robinson et al.[25] performed a thirteen-year observational cohort study of 163 consecutive patients treated with hemiarthroplasty for a proximal humeral fracture. They found that the results are poorer in the larger group of elderly patients who undergo this procedure, especially if they have a neurological deficit, a postoperative complication requiring a reoperation, or an eccentrically located prosthesis with retracted tuberosities. While a good functional outcome can be anticipated for a younger individual. In our study, age was a risk factor for the surgery. The influence of age on the predicted outcome is likely to reflect many factors that adversely affect outcome, including degenerative change within the rotator cuff, osteoporosis, and the lack of motivation to achieve a range of motion beyond the limited functional needs of an elderly patient. In another, the elder patients' expectation for postoperative functional recovery of shoulder joint are lower than young patients'. Thus, the postoperative functional exercise is not active as young patients. Therefore, some experts suggest conservative treatment should be considered for the elderly patients with lower functional requirements and who can accept the painless and function limited shoulder joint[26].

The results of this study showed that time from injury to surgery was the second risk factor to affect the treatment of humeral head replacement, with $O R=18.411, P<0.05$. Bosch, et al.[27] compared patients in whom hemiarthroplasty was performed $<4$ weeks after injury with patients in whom hemiarthroplasty was performed $>4$ weeks after injury. They found the outcome after early ( $<4$ weeks) humeral head replacement was significantly better than after late ( $>$ or $=4$ weeks) humeral head replacement with California-Los Angeles scale, Constant-Murley scale and active forward flexion. Gronhagen et al[28] believed that surgery should be performed as soon as possible after injury. Maybe the soft tissue adhesion will widely formed with the late surgery, which will influence the shoulder activity range and 
rotator cuff reconstruction. What's more, muscle atrophy and extensive adhesions around the shoulder will seriously affect the shoulder joint postoperative functional exercise. Thus, the decision to perform prosthetic humeral head replacement should be made as early as possible after trauma.

This study showed that early exercise was the third risk factor to affect the treatment of humeral head replacement, with $\mathrm{OR}=16.772, \mathrm{P}<0.05$. Field et al. [29] believes that the time to start exercising after surgery depend on the patient's actual condition. Handoll, et al.[30] made a system review to investigate interventions for treating proximal humeral fractures in adults. In the results, 4 trials compared early (usually one week) versus delayed (three or four weeks) mobilisation after fracture but only limited pooling was possible and most of the data were from one trial (86 participants). This found some evidence that early mobilisation resulted in better recovery and less pain in people with mainly minimally displaced fractures. In our opinion, early shoulder joint exercise can be effective to reduce the adhesion of soft tissue around the shoulder joint. So, we recommend that the appropriate strength of functional exercise should be performed as soon as possible after humeral head replacement surgery.

This study also found that regular outpatient follow-up was a protective factor to affect the treatment of humeral head replacement, with $\mathrm{OR}=0.088, \mathrm{P}<0.05$. Grönhagen et al.[28] performed a study of mediumterm results after primary hemiarthroplasty for comminute proximal humerus fractures with regular outpatient follow-up. The mean time for physiotherapy was 27 weeks in 58 patients, working with a physiotherapist 1 to 2 times a week. Most of the patients still did at follow-up. Their results showed hemiarthroplasty usually prevented shoulder pain with moderate function. In our experience, with regular follow-up, a lot of problems can be solved timely. Therefore, we suggested that the time of regular outpatient follow-up should not less than 2 years.

Our study could not find osteoporosis was a risk factor to affect the treatment of humeral head replacement. Hemiarthroplasty is frequently used in situations of severe comminution, concern for humeral head ischemia, and poor bone quality[6]. The tenuous fixation of fracture fragments in osteoporotic bone have led most surgeons to advocate hemiarthroplasty as the preferred option over internal fixation[7]. Beaudreuil et al[31] hold that when proximal humeral fracture patients with osteoporosis, even if the fracture fragment is reduced effectively, it is still hard to fix it steadily, and patient with osteoporosis will increase the difficulty of rotator cuff reconstruction and the risk of the postoperative reinjury of rotator cuff and intra-articular loose. However, our result found that osteoporosis was not a significant for the functional outcome. Maybe we used the cement in the operation, so there were few complications of intra-articular loose in our study. Or the sample population was to small to draw the conclusion about the osteoporosis affecting the outcomes.

Several limitations associated with this study warrant mention. Firstly, the sample population was small, which may increase the occurrence of standard errors and type II errors, and the population of patients was heterogeneous, and the results of our study may be affected by confounding variables. Secondly, this study was retrospective with certain selection biases and missing data. A prospective study with more patients should be performed to confirm the results in the future. 


\section{Conclusion}

The main factors that influence the efficacy of humeral head replacement are age, time from injury to surgery, time to start exercising after surgery, and whether regular outpatient follow-up, and they should be taken into consideration for individualized treatment.

\section{Abbreviations}

VSA: Visual Analogue Scale; ASES: American Association of Shoulder and Elbow Surgery; PROCESS: Preferred reporting of case series in surgery; SPSS: Statistical Product and Service Solutions

\section{Declarations}

\section{Ethics and consent to participate}

The study was approved by the Research Ethics Boards of the Second Affiliated Hospital of Wenzhou Medical University. Informed consent was waivered by the above ethics committee as the present retrospective cohort study involved already existing data and records at the time of investigation, and did not retain personal identifiers of the gathered information.

\section{Consent for publication}

Not applicable.

\section{Availability of data and materials}

The datasets used and analysed during the current study available from the corresponding author on reasonable request.

\section{Competing interests}

The authors declare no competing financial interests.

\section{Funding}

This study was funded by National Nature Foundation of China (Grant No.81472146), and Wenzhou Science and Technology Bureau Foundation (Grant No. Y20160135). These two institutions were not involved in the study design, data analyses, interpretation of the data, or writing of the manuscript.

\section{Authors' contributions}

H.C and C.H.C conceived and designed the experiments. L.Y.C and L.Z.X collected the data. W.H.Z analyzed the data. C.H.C wrote the paper. All authors reviewed the manuscript.

\section{Acknowledgements}


The authors thank all the staff in the Laboratory of Orthopaedic Research Institute and Scientific Research Center of the Second Affiliated Hospital and Yuying Children's Hospital of Wenzhou Medical University.

\section{Disclosure Statement}

The authors declare no competing financial interests.

\section{References}

1. McKoy BE BC, Hartsock LA. Fractures about the shoulder: conservative management. The Orthopedic clinics of North America. 2000; 31(2):205-216.

2. Cadet ER and Ahmad CS. Hemiarthroplasty for three- and four-part proximal humerus fractures. The Journal of the American Academy of Orthopaedic Surgeons. 2012; 20(1):17-27.

3. Handoll HHG and Ollivere BJ. Interventions for treating proximal humeral fractures in adults. Cochrane Db Syst Rev. 2010; (12).

4. Kannus $\mathrm{P}$, Palvanen $\mathrm{M}$, Niemi $\mathrm{S}$, Sievanen $\mathrm{H}$ and Parkkari J. Rate of proximal humeral fractures in older Finnish women between 1970 and 2007. Bone. 2009; 44(4):656-659.

5. Myeroff CM AJ, Sveom DS, Switzer JA. Predictors of Mortality in Elder Patients With Proximal Humeral Fracture. Geriatr Orthop Surg Rehabil. 2017; 31;9:( 31;9:):2151458517728155.

6. Maier D, Jaeger M, Izadpanah K, Strohm PC and Suedkamp NP. Proximal humeral fracture treatment in adults. The Journal of bone and joint surgery American volume. 2014; 96(3):251-261.

7. Zyto K, Wallace WA, Frostick SP and Preston BJ. Outcome after hemiarthroplasty for three- and fourpart fractures of the proximal humerus. Journal of shoulder and elbow surgery. 1998; 7(2):85-89.

8. Harrold $\mathrm{F}$ and Wigderowitz $\mathrm{C}$. Humeral head arthroplasty and its ability to restore original humeral head geometry. Journal of shoulder and elbow surgery. 2013; 22(1):115-121.

9. Kwon YW and Zuckerman JD. Outcome after treatment of proximal humeral fractures with humeral head replacement. Instructional course lectures. 2005; 54:363-369.

10. Pavlopoulos DA, Badras LS, Georgiou CS, Skretas EF and Malizos KN. Hemiarthroplasty for threeand four- part displaced fractures of the proximal humerus in patients over 65 years of age. Acta orthopaedica Belgica. 2007; 73(3):306-314.

11. Mehlhorn AT, Schmal H and Sudkamp NP. Clinical evaluation of a new custom offset shoulder prosthesis for treatment of complex fractures of the proximal humerus. Acta orthopaedica Belgica. 2006; 72(4):387-394.

12. Frombach AA, Brett $K$ and Lapner P. Humeral Head Replacement and Reverse Shoulder Arthroplasty for the Treatment of Proximal Humerus Fracturesm. The open orthopaedics journal. 2017; 11:11081114.

13. Hasan SS, Leith JM, Campbell B, Kapil R, Smith KL and Matsen FA, 3rd. Characteristics of unsatisfactory shoulder arthroplasties. Journal of shoulder and elbow surgery. 2002; 11(5):431-441. 
14. Agha RA, Fowler AJ, Rajmohan S, Barai I, Orgill DP and Group P. Preferred reporting of case series in surgery; the PROCESS guidelines. International journal of surgery. 2016; 36(Pt A):319-323.

15. Richards RR, An KN, Bigliani LU, Friedman RJ, Gartsman GM, Gristina AG, lannotti JP, Mow VC, Sidles JA and Zuckerman JD. A standardized method for the assessment of shoulder function. Journal of shoulder and elbow surgery. 1994; 3(6):347-352.

16. Reed MD and Van Nostran W. Assessing Pain Intensity With the Visual Analog Scale: A Plea for Uniformity. J Clin Pharmacol. 2014; 54(3):241-244.

17. Neer CS. Displaced proximal humeral fractures - Part I. Classification and evaluation (Reprinted from Clinical Orthopaedics and Related Research, Oct, 1987). Clinical orthopaedics and related research. 2006; (442):77-82.

18. Neer CS, 2nd. Displaced proximal humeral fractures. II. Treatment of three-part and four-part displacement. The Journal of bone and joint surgery American volume. 1970; 52(6):1090-1103.

19. Suzuki T, Iwamoto T, Shizu K, Suzuki K, Yamada H and Sato K. Predictors of postoperative outcomes of cubital tunnel syndrome treatments using multiple logistic regression analysis. J Orthop Sci. 2017; 22(3):453-456.

20. Chiu YJ, Liao WC, Wang TH, Shih YC, Ma H, Lin CH, Wu SH and Perng CK. A retrospective study: Multivariate logistic regression analysis of the outcomes after pressure sores reconstruction with fasciocutaneous, myocutaneous, and perforator flaps. J Plast Reconstr Aes. 2017; 70(8):1038-1043.

21. Sun LJ, Wu ZP, Yang J, Tian NF, Yu XB, Hu W, Guo XS and Chen H. Factors associated with a failed closed reduction for supracondylar fractures in children. Orthop Traumatol-Sur. 2014; 100(6):621624.

22. Konrad GG, Mehlhorn A, Kuhle J, Strohm PC and Sudkamp NP. Proximal humerus fractures - current treatment options. Acta chirurgiae orthopaedicae et traumatologiae Cechoslovaca. 2008; 75(6):413421.

23. Badman BL and Mighell M. Fixed-angle locked plating of two-, three-, and four-part proximal humerus fractures. The Journal of the American Academy of Orthopaedic Surgeons. 2008; 16(5):294-302.

24. Kontakis GM, Damilakis J, Christoforakis J, Papadakis A, Katonis P and Prassopoulos P. The bicipital groove as a landmark for orientation of the humeral prosthesis in cases of fracture. Journal of shoulder and elbow surgery. 2001; 10(2):136-139.

25. Robinson CM, Page RS, Hill RMF, Sanders DL, Court-Brown CM and Wakefield AE. Primary hemiarthroplasty for treatment of proximal humeral fractures. Journal Of Bone And Joint SurgeryAmerican Volume. 2003; 85A(7):1215-1223.

26. Rangan A, Handoll H, Brealey S, Jefferson L, Keding A, Martin BC, Goodchild L, Chuang LH, Hewitt C, Torgerson D and Collaborators PT. Surgical vs nonsurgical treatment of adults with displaced fractures of the proximal humerus: the PROFHER randomized clinical trial. Jama. 2015; 313(10):1037-1047.

27. Bosch U, Skutek M, Fremerey RW and Tscherne H. Outcome after primary and secondary hemiarthroplasty in elderly patients with fractures of the proximal humerus. Journal of shoulder and 
elbow surgery. 1998; 7(5):479-484.

28. Gronhagen $\mathrm{CM}$, Abbaszadegan $\mathrm{H}$, Revay SA and Adolphson PY. Medium-term results after primary hemiarthroplasty for comminute proximal humerus fractures: a study of 46 patients followed up for an average of 4.4 years. Journal of shoulder and elbow surgery. 2007; 16(6):766-773.

29. Field LD, Dines DM, Zabinski SJ and Warren RF. Hemiarthroplasty of the shoulder for rotator cuff arthropathy. Journal of shoulder and elbow surgery. 1997; 6(1):18-23.

30. Handoll $\mathrm{HH}$ and Brorson S. Interventions for treating proximal humeral fractures in adults. The Cochrane database of systematic reviews. 2015; (11):CD000434.

31. Beaudreuil J OA, Lasbleiz S, Vicaut E, Yelnik A, Bardin T, Orcel P. Efficacy of dynamic humeral centering according to Neer test results: a stratified analysis of a randomized-controlled trial.Int $\mathrm{J}$ Rehabil Res. 2015; 38(1)(38(1)):81-83. 